\title{
Prediction of Solar Radiation for the Major Climates of Jordan: A Regression Model
}

\author{
Ali A. Badran ${ }^{1 *}$, Belal F. Dwaykat ${ }^{2}$ \\ 1 Department of Mechanical Engineering, Philadelphia University, Amman, Jordan \\ 2 Deparrtment of Mechanical Engineering, Energy Management Program, University of Jordan, Amman, Jordan \\ * Corresponding author's e-mail: abadran@philadelphia.edu.jo
}

\begin{abstract}
Multiple regression models were developed for calculating the regression coefficients $a$ and $b$ of the Angström-type equation for estimating the monthly average daily global radiation on a horizontal surface for six major climates in Jordan. The equations for $a$ and $b$ were developed from the available values of these constants reported in the literature for locations across the country, along with the sunshine duration and the values of ground albedo $\left(\rho_{\mathrm{g}}\right)$. The developed correlations were tested for their applicability by estimating the regression constants and the solar radiation for six locations spread over the country, which were Irbid, Amman, Azraq, Al-Shawbak, Ma'an and Aqaba. The remarkable agreement between the estimated and experimental data of solar radiation in those locations suggests a wide applicability of the method for the locations with sunshine duration ranging from 0.7 to 0.8 . The maximum and minimum percentages of error for those locations were found to be $6.3,0.05 \%$, respectively.
\end{abstract}

Keywords: solar radiation, regression model, climate in Jordan

\section{INTRODUCTION}

The amount of energy incident on the earth's surface is rarely available and recorded only in specific locations, particularly in developing regions such as Jordan. However, solar radiation measuring equipment requires regular maintenance and calibration not to mention their high costs. One of the most well-known and simplest methods is the relationship (1) developed by Angström (1924):

$$
H / H_{0}=a+b\left(n / N_{0}\right)
$$

where: $a$ and $b$ are coefficients that are given for the location in question and are shown in Table 1,

$H_{0}$ - the monthly average daily extraterrestrial radiation on a horizontal surface, $\mathrm{MJ} / \mathrm{m}^{2}$.daily

$H$ - monthly mean daily solar radiation on horizontal surface, $\mathrm{MJ} / \mathrm{m}^{2}$.daily

$n$ - monthly mean daily hours of bright sunshine, hours
$N_{0}$ - Monthly average of maximum possible daily hours of bright sunshine (day length)

The coefficients $a$ and $b$ are shown in the last two columns of the Table. Unfortunately, it covers only 18 major locations in the world, and none of these is in Jordan or even nearby. The first two columns are concerned with climate types and vegetation, as illustrated by Table 2 (Duffie and Beckman, 2006).

For example, Jordan's climate may be classified as desert or arid climate (BW) and its vegetation as broad leaf deciduous, shrub form, with the minimum height of plants reaching $3 \mathrm{ft}$, sufficiently far apart that they frequently do not touch (Dsi). In other words, the location in Table 1 that best simulates the climate type of Jordan is El Paso, Texas.

Rietveld (1978) analyzed various published values and noted that $a$ is related linearly and $b$ hyperbolically to the appropriate mean values of $\left(\mathrm{n} / \mathrm{N}_{0}\right)$. The results were shown in equations (3) and (4): 
Table 1. Climatic coefficients for use in Eq. 1 (Duffie and Beckman, 2006)

\begin{tabular}{|c|c|c|c|c|c|c|}
\hline \multirow[t]{2}{*}{ Location } & \multirow[t]{2}{*}{ Climate $^{a}$} & \multirow[t]{2}{*}{ Veg. ${ }^{b}$} & \multicolumn{2}{|c|}{$\begin{array}{c}\text { Sunshine hours } \\
\text { in percentage of possible }\end{array}$} & \multirow[t]{2}{*}{$a$} & \multirow[t]{2}{*}{$b$} \\
\hline & & & Range & Avg. & & \\
\hline Albuquerque, NM & BS-BW & $E$ & $68-85$ & 78 & 0.41 & 0.37 \\
\hline Atlanta, GA & Cf & $\mathrm{M}$ & $45-71$ & 59 & 0.38 & 0.26 \\
\hline Blue Hill, MA & Df & $\mathrm{D}$ & $42-60$ & 52 & 0.22 & 0.50 \\
\hline Brownsville, TX & BS & GDsp & $47-80$ & 62 & 0.35 & 0.31 \\
\hline Buenos Aires, Arg. & $\mathrm{Cf}$ & G & $47-68$ & 59 & 0.26 & 0.50 \\
\hline Charleston, SC & $\mathrm{Cf}$ & $E$ & $60-75$ & 67 & 0.48 & 0.09 \\
\hline Darien, Manchuria & Dw & D & $55-81$ & 67 & 0.36 & 0.23 \\
\hline EI Paso, TX & BW & Dsi & $78-88$ & 84 & 0.54 & 0.20 \\
\hline Ely, NV & BW & Bzi & $61-89$ & 77 & 0.54 & 0.18 \\
\hline Hamburg, Germany & Cf & $\mathrm{D}$ & $11-49$ & 36 & 0.22 & 0.57 \\
\hline Honolulu, HI & Af & G & $57-77$ & 65 & 0.14 & 0.73 \\
\hline Madison, WI & Df & M & $40-72$ & 58 & 0.30 & 0.34 \\
\hline Malange, Angola & Aw-BS & GD & $41-84$ & 58 & 0.34 & 0.34 \\
\hline Miami, FL & Aw & E-GD & $56-71$ & 65 & 0.42 & 0.22 \\
\hline Nice, France & Cs & SE & $49-76$ & 61 & 0.17 & 0.63 \\
\hline Poona, India (Monsoon) & $\mathrm{Am}$ & $S$ & $25-49$ & 37 & 0.30 & 0.51 \\
\hline (Dry) & & & $65-89$ & 81 & 0.41 & 0.34 \\
\hline Kisangani, Zaire & Af & B & $34-56$ & 48 & 0.28 & 0.39 \\
\hline Tamanrasset, Algeria & BW & Dsp & $76-88$ & 83 & 0.30 & 0.43 \\
\hline
\end{tabular}

Table 2. Climate types and vegetation (ground cover) to be used along with Table 1

"Climatic classification based on Trewartha's map $(1954,1961)$, where climate types are:

Af Tropical forest climate, constanty moist; $r$ anf all throughout the year

Am Tropical forest elimate, monsoon rain; short dry season, but total rainfall sufficient to support rain forest

Aw Tropical forestelimate, dry season in winter

BS Steppe or semiarid climate

BW Desert or arid climate

Cf Mesothermal forest climate; constanty moist; rainf all throughout the year

Cs Mesothermal forest climate; dry season in winter

Df Micro thermal snow forest climate; constantly moist, rainfall throughout the year

Dw Microthermal snow forestelimate; dry season in winter

${ }^{b}$ Vegetation classification based on Küchler's map, where vegetat ion types are:

B Broadleaf evergreen trees

Bzi Broadleaf evergreen, shrub form, minimum height $3 \mathrm{ft}$, growth singly or in groups or patehes

D Broadleaf deciduous trees

Dsi Broadleaf deciduous, shrub form, minimum height $3 \mathrm{ft}$, plants sufficienty far apart that they frequently do not touch

Dsp Broadleaf deciduous, shrub form, minimum height $3 \mathrm{ft}$, growth singly or in groups or patches

E Needleleaf evergreen trees

G Grass and other herbaceous plants

GD Grass and other herbaceous plants; broadleaf deciduous trees

GDsp Grass and other herbaceous plants; broadleaf deciduous, shrub forms, minimum height $3 \mathrm{ft}$, growth singly or in groups or patehes

M. Mixed broadleaf deciduous and needle leaf evergreen trees

S Semideciduous: broadleaf evergreen and broadleaf deciduous trees

SE Semideciduous: broadleaf evergreen and broadleaf deciduous trees: needleleaf evergreen trees

Note: These constants are based on radiation data available before 1966 and do not reflect improvements in data processing and interpretation made since then. The results of estimations for U.S. stations will be at variance with TMY2 data. It is recommended that these correlations be used only when there are no radiation data available. 


$$
\begin{aligned}
& a=0.1+0.24\left(\frac{n}{N_{0}}\right) \\
& b=0.38+0.08\left(\frac{n}{N_{0}}\right)
\end{aligned}
$$

Hay (1979) developed a model that takes into account the optical properties of the cloud cover, ground reflectivity, and average air mass as in Eqn. 5 and 6:

$$
\frac{H}{H_{0}}=\frac{0.1572+0.5566\left(\frac{n}{N_{0}}\right)}{1-\rho\left[\rho_{a}\left(\frac{n}{N}\right)+\rho_{\mathrm{c}}\left(1-\frac{n}{N}\right)\right]}
$$

$$
\begin{aligned}
& N_{\mathrm{o}}=\frac{1}{7.5} \cos ^{-1}\left[\left(\cos 85-\sin \phi \sin \delta_{\mathrm{c}}\right) /\right. \\
& \left./\left(\cos \phi \cos \delta_{\mathrm{c}}\right)\right]
\end{aligned}
$$

Where $\rho$ is the ground Albedo, $\rho_{a}$ is the cloudless-sky Albedo and $\rho_{c}$ is the cloud Albedo. The values of these factors are assigned to 0.2, 0.25, and 0.6 , respectively, $\delta_{c}$ is characteristic declination, $N$ is the modified day length and excludes the fraction during which the solar zenith angle is greater than 85 degrees.

Gariepy (1980) proposed a model for (a) and (b) which are dependent on the average temperature of the air and the precipitation amount as in Equations 7 and 8:

$$
\begin{aligned}
& a=0.3791-0.0041 T-0.0176 P \\
& b=0.4810-0.0043 T-0.0097 P
\end{aligned}
$$

where: $T$ is the temperature,

$P$ is the amount of precipitation.

Zabara (1986) developed models for the coefficients $a$ and $b$ of the modified Angström model as a third order function of sunshine duration as in Eqns. 9 and 10:

$$
\begin{aligned}
& a=0.395-1.247 \frac{n}{N_{\mathrm{o}}}+2.68\left(\frac{n}{N_{\mathrm{o}}}\right)^{2}- \\
& -1.674\left(\frac{n}{N_{\mathrm{o}}}\right)^{3} \\
& b=0.395+1.384 \frac{n}{N_{\mathrm{o}}}-3.249\left(\frac{n}{N_{\mathrm{o}}}\right)^{2}+ \\
& +2.055\left(\frac{n}{N_{\mathrm{o}}}\right)^{3}
\end{aligned}
$$

Gopinathan (1988) obtained a model which is considered as the most accurate model for estimation $H$ for New Delhi through equation 11:

$$
\begin{aligned}
& \frac{H}{H^{0}}=\left(-0.309+0.539 \cos \phi-0.0693 Z+0.29 \frac{n}{N^{0}}\right)+ \\
& +\left(1.527-1.027 \cos \phi+0.0926 Z-0.359 \frac{n}{N_{0}}\right) \frac{n}{N_{0}}
\end{aligned}
$$

where: $Z$ is altitude in kilometers.

Tiwari et al, (1997) developed a relationship for (a) and (b) coefficients that are function of $\Phi$, the location latitude as follows:

$$
\begin{aligned}
& a=-0.11+0.235 \cos \phi+0.323\left(\frac{n}{N_{\mathrm{o}}}\right) \\
& b=1.449-0.553 \cos \phi+0.694\left(\frac{n}{N_{\mathrm{o}}}\right)
\end{aligned}
$$

El-Sebaii and Trabea (2005) studied a measured data of $H$ and the number of sunshine hours in five Egyptian locations: Matruh, Rafah, AlArish, Tanta and Aswan, They investigated the first, second and third order relationships and found that the second and the third do not improve the accuracy of the model. The coefficients of the suggested first order model for Egypt are $a$ $=0.3647$ and $b=0.3505$.

Assc and Jama, M. (2009) estimated the coefficients $a$ and $b$ of the Angström regression model for two cities in United Arab Emirates (UAE) where $a=0.1833, b=0.5301$ for Abu Dabi and $a$ $=0.183, b=0.6478$ for Al-Ain.

On the local level, several works were performed on predicting solar radiation, started by Al-Sa'ad (1990,1991, 1993), Gibril (1991), Hammad and Al-Sayeh (1991), Hamdan and Gazzawi, (1993), Hamdan (1994).

Al-Muhtaseb (2012) developed multiple regression models for four cities in Jordan using four independent variables which were weather condition parameters, including: sunshine duration, relative humanity, average temperature and $\max / \min$ temperature ratio. The intercept and the coefficients are as the following:

- Irbid: $a=0.12, b=0.87, c=0.27, d=-0.003$, $e=-0.335$

- Amman: $a=-0.059, b=1.12, c=-0.0019, d$ $=-0.009, e=-0.128$

- Azraq: $a=0.24, b=-0.034, c=0.427, d$ $=-0.0065, e=0.002$

- Showbak: $a=0.05, b=0.53, c=0.283, d=$ $0.009, e=-0.267$ 
Al-Muhtaseb also used the Angström regression model and developed new constants for the model for five locations in Jordan and, as a result, the $a$ and $b$ constants for Jordan are 0.279 and 0.489 respectively.

All of these works did not take into account the effect of climate type and vegetation, or ground cover, in the considered region. In this work, these effects will be taken taken into consideration for the first time in six regions of Jordan, mainly Irbid, Amman, Azraq, Showbak, $\mathrm{Ma}$ 'an and Aqaba.

\section{THEORETICAL ANALYSIS}

The major driver of the Earth's climate and weather is the solar radiation, the energy rate which reaches the Earth is roughly $340 \mathrm{~W} / \mathrm{m}^{2}$, some of it is reflected back to space which is around one-third and while the remaining 240 $\mathrm{W} / \mathrm{m}^{2}$ is absorbed by the atmosphere, ocean and land, the amount of absorbed energy depends on the surface and the atmosphere reflectivity.

An energy balance is used by researchers and scientists using the so-called Clouds and the Earth's Radiant Energy System (CERES) which is a series of space-based sensors. Such sensors measure the reflected radiation from the Earth as a shortwave radiation (Albedo) and the thermal energy that the Earth emits as a long wave.

The albedo of the Earth, as indicated by $\rho_{\mathrm{g}}$ is about 0.84 if its surface is completely covered by snow; 0.85 of the sunlight which hit it would be reflected. On the other hand Earth with a green forest canopy covering its surface is characterized by albedo of 0.14 , as most of the solar radiation would be absorbed.

Table 3 provides the values of Albedo for different cities, depending on the ground cover maps, vegetation maps, albedo tables and albedo data from NASA Earth Observatory (NEO).

A series of ground cover maps were released in 2006 by the Royal Jordanian Geographic Center (RJGC), based on the usage of digital classification of Landsat satellite images. Ground cover was divided into 18 classes which is a standard developed by the European Environmental Agency (EEA). Figure 1 was drawn by International Foundation for Protection Officers (IFPO) and RJGC shows the extracted 18 classes of the ground cover in Jordan. The map is considered as a part of the Atlas of Jordan. Three-quarters of the land is covered with bare rocks, chert plains, granite rock, sand and bare soil. Wadis and mudflats cover more than $14 \%$ of Jordan land where the vegetation is dense.

A more detailed map about desert, ground cover, as well as the irrigated and urban areas was produced by Al-Bakri et al. (2013), as shown in Figure 2. Jordan is also classified into various vegetation regions which are shown in Figure 3.

Vegetation may be expressed by Normalized Difference Vegetation Index (NDVI), which is considered as a method to represent the vegetation level in a certain location. It is an index that indicates if the studied location includes green vegetation by analyzing remote sensing records; it can be obtained by means of equation (14).

$$
\mathrm{NDVI}=\left(\rho_{\mathrm{NIR}}-\rho_{\text {red }}\right) /\left(\rho_{\mathrm{NIR}}+\rho_{\text {red }}\right)
$$

where: $\rho$ red is the spectral reflectance records acquired in the red region and $\rho N I R$ is the spectral reflectance records acquired in near-infrared region

Figure 4 represents values of NDVI which are 0.72 and 0.14 for a healthy and unhealthy vegetation, respectively.

Dense vegetation canopy has positive index values (0.33 to 0.85$)$, whereas clouds and snow fields have a negative index.

The climate across Jordan, based on the rain distribution, is considered to be of the Mediterranean variety because the rainfall mainly occurs in winter and spring, despite Jordan is divided into nine bioclimatic regions, including:

1. Sub-humid Mediterranean bioclimate, cool and warm varieties, such as Ras Muneef and Ajloun.

2. Semi-arid Mediterranean bioclimate, warm variety, such like in Irbid, Amman, Madaba, Taybeh and Baka'a.

3. Semi-arid Mediterranean bioclimate, cool variety, such as in Showbak and Tafileh.

4. Arid Mediterranean bioclimate, cool variety,

Table 3. Albedo values for the selected locations

\begin{tabular}{|l|c|}
\hline \multicolumn{1}{|c|}{ Location } & Albedo \\
\hline Irbid & 0.17 \\
\hline Amman & 0.20 \\
\hline Azraq & 0.25 \\
\hline Showbak & 0.26 \\
\hline Ma'an & 0.38 \\
\hline Aqaba & 0.23 \\
\hline
\end{tabular}




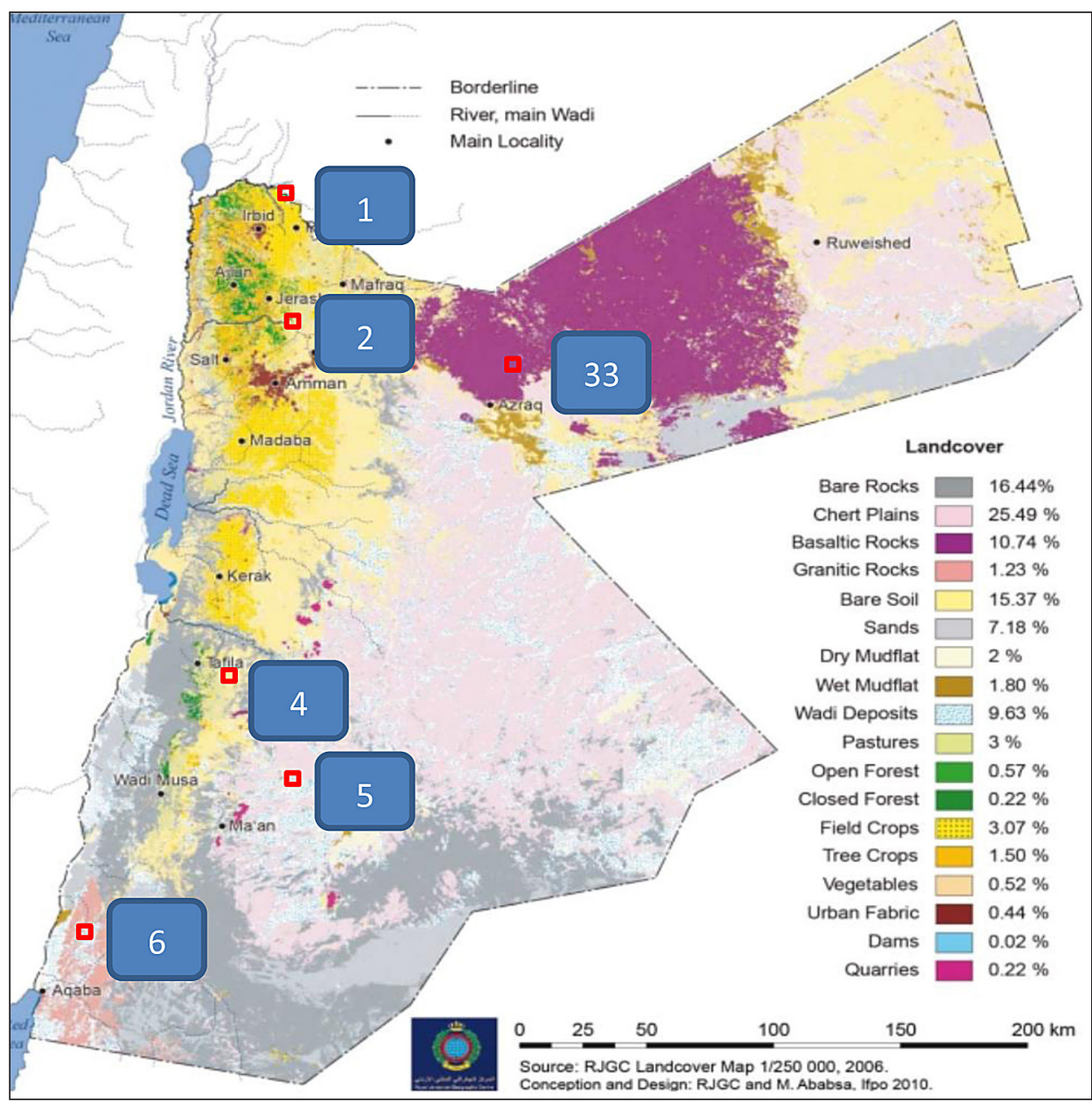

Figure 1. Jordan land cover based on Landsat Satellites Image (RJGC)

such as in Mafraq, Al-Jiza, Al-Qurein and wadi-Dhuleil.

5. Arid Mediterranean bioclimate, which falls in between the cool and warm variety, such as in Zarka and Ramtha.

6. Arid Mediterranean bioclimate, which falls in between the warm and very warm, such as in Dair'Alla. AL-Baqura, Shuneh North and Wadi-yabis.

7. Saharan Mediterranean bioclimate, as in ALJafr, Ma'an, and Azraq.

8. Saharan Mediterranean bioclimate, warm variety (a belt of land with an average width of 20 $\mathrm{km}$ along the Eastern Hills).

9. Saharan Mediterranean bioclimate, very warm variety, such as in Ghor Safi, Wadi-Araba and Aqaba.

Regression analysis is a statistical method for predicting the relationships between variables. There are many techniques for studying and modeling the variables, the relationship between the dependent and independent variable is important, more specifically, the regression analysis shows how the value of the dependent variable changes when the value of one independent is variable while the other independent variable is fixed. The regression analysis provides the knowledge pertaining to which independent variables are of major effect on the dependent variable among various variables and examining the forms of the relationships which relate the independent with the dependent variables.

In the case of linear regression model, there is one independent variable that has a linear relationship with one dependent variable; there is one independent variable $X_{i}$, and two parameters, $\beta_{0}$ and $\beta_{1}$ for modeling $\mathrm{n}$ data:

$$
Y_{i}=\beta_{0}+\beta_{1} X_{i}+\varepsilon_{i}, i=1, \ldots, n
$$

where: $\varepsilon_{i}$ - the error term and the subscript $Y_{i}$ which represents a specific observation. $Y_{i}-$ the dependent variable.

In multiple liner regression, there are many independent variables. 


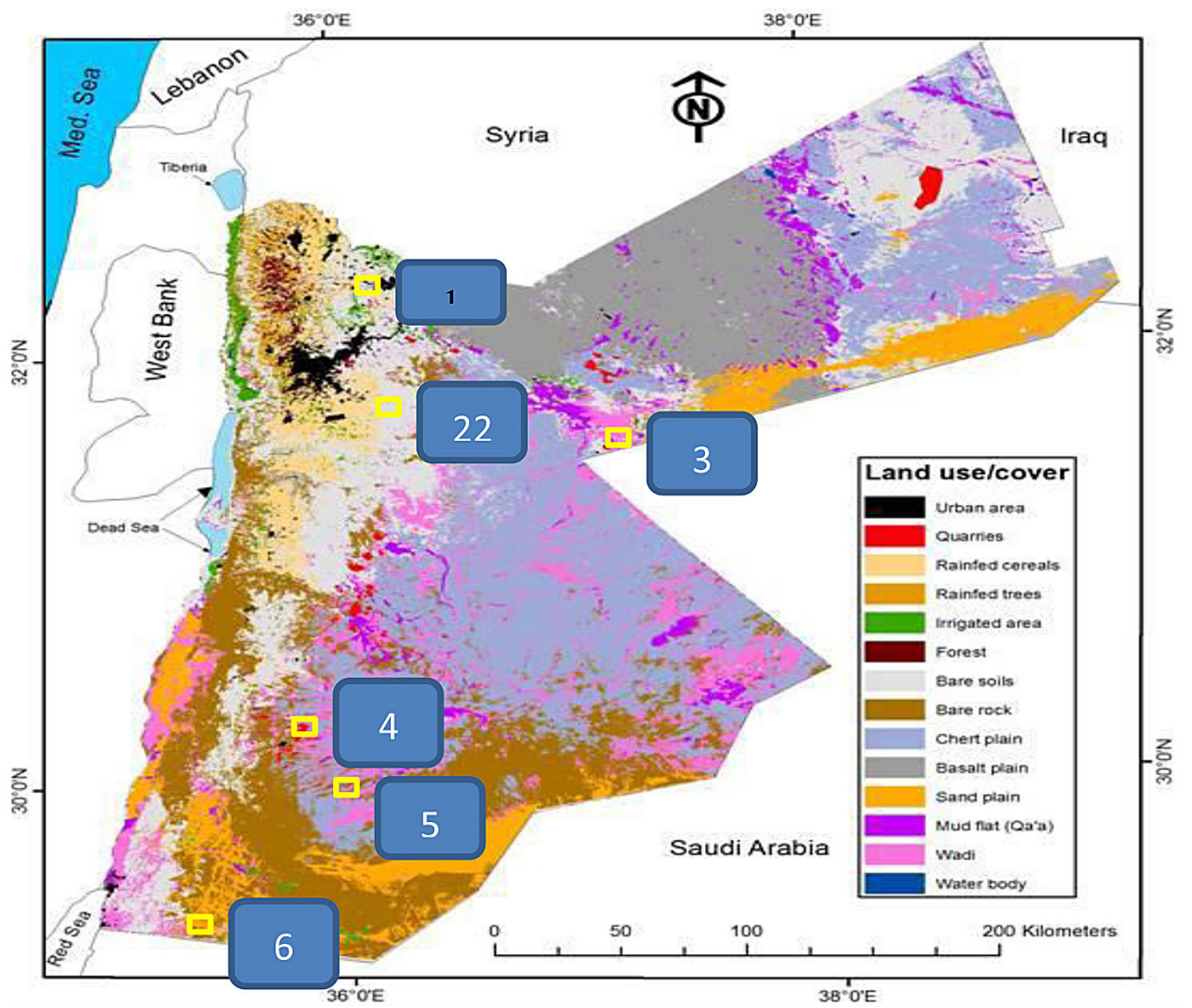

Figure 2. Modified ground cover map of Jordan (Al-Bakri et al., 2013).

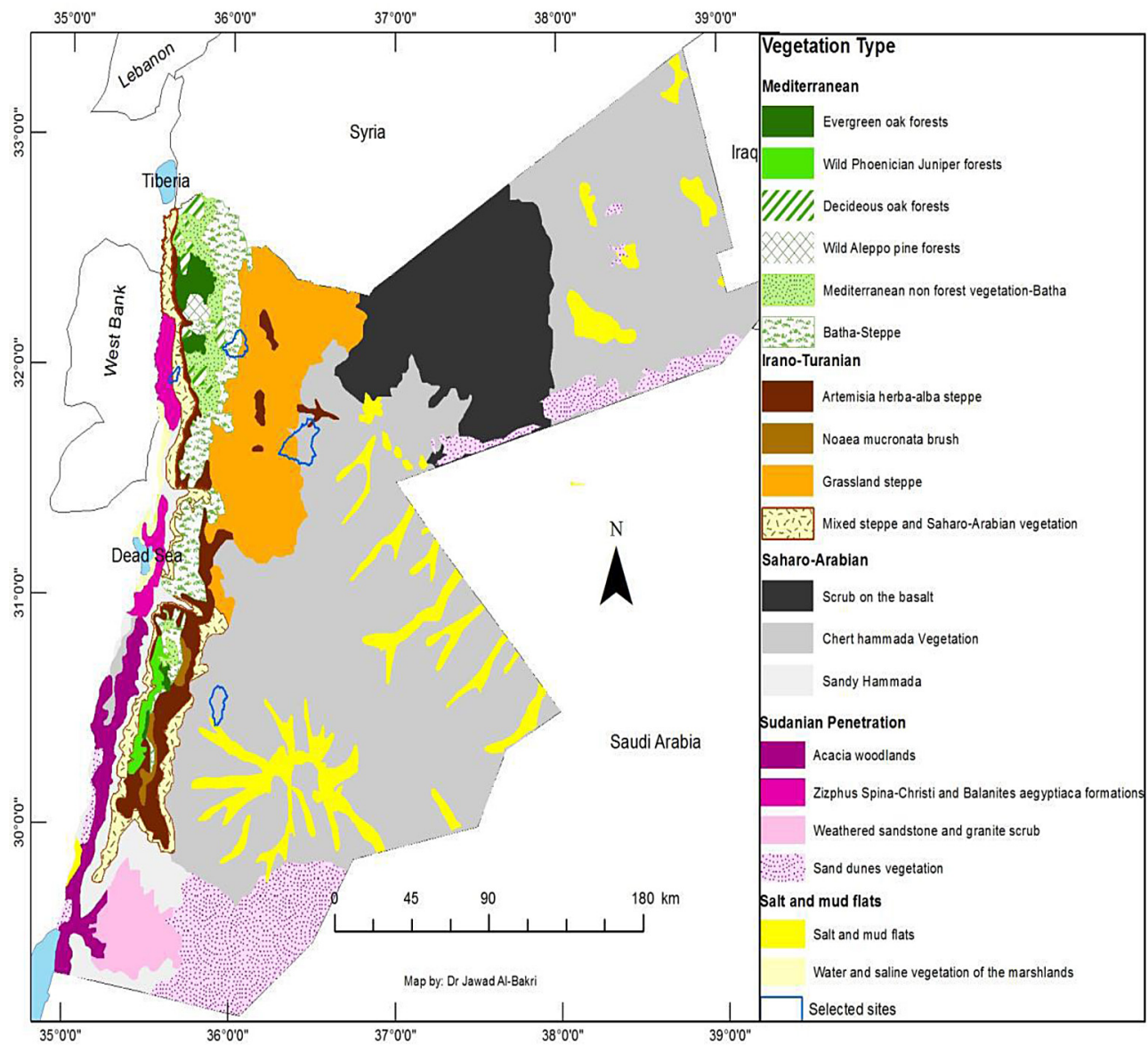

Figure 3. Vegetation map of Jordan (Al-Bakri et al., 2013) 
Inclusuion of the term $X_{i}^{2}$ to the previous regression results in:

$$
\begin{aligned}
& \text { Parabola: } Y_{i}=\beta_{0}+\beta_{1} X_{i}+\beta_{2} X_{i}^{2}+ \\
& +\varepsilon_{i}, i=1, \ldots, n
\end{aligned}
$$

This remains linear regression, despite that the right side is quadratic in the independent variable $X_{i}$, and it is linear in the parameters $\beta_{0}$ and $\beta_{1}$ and $\beta_{2}$.

In the first case of linear regression, equation (17) is used to predict the population parameters.

$$
\widehat{Y_{l}}=\widehat{\beta_{0}}+\widehat{\beta_{1}} X_{i}
$$

The residual is given by equation (18) and it represents the difference between the value of the dependent variable estimated by the model $\widehat{Y}_{l}$ and the real value of the dependent variable $Y_{i}$.

$$
e_{i}=Y_{i}-\widehat{Y}_{l}
$$

One method of prediction is the ordinary least squares. This method produces a parameter esti- mates that minimizes the sum of squared residuals (SSE) which is given by:

$$
S S E=\sum_{i=1}^{n} e_{i}^{2}
$$

Minimization of this term leads in a set of normal equations, a set of simultaneous linear equations in the parameters, which are solved to yield the parameter estimators $\widehat{\beta_{0}}, \widehat{\beta_{1}}$

Figure 5 represents an illustration of a linear regression model on a data set.

In the case of a simple regression, the formulas for the least squares estimates are:

$$
\begin{gathered}
\widehat{\beta_{1}}=\frac{\sum\left(X_{i}-\hat{X}\right)\left(Y_{i}-\widehat{Y}_{l}\right)}{\sum\left(X_{i}-\hat{X}\right)^{2}} \\
\widehat{\beta_{0}}=\hat{Y}-\widehat{\beta_{1}}
\end{gathered}
$$

Where $\hat{X}$ is the average of the $X$ values and $\hat{Y}$ is the mean of the $Y$ values.

Under the assumption that the population error term has a constant variance, the estimate of that variance is given by:

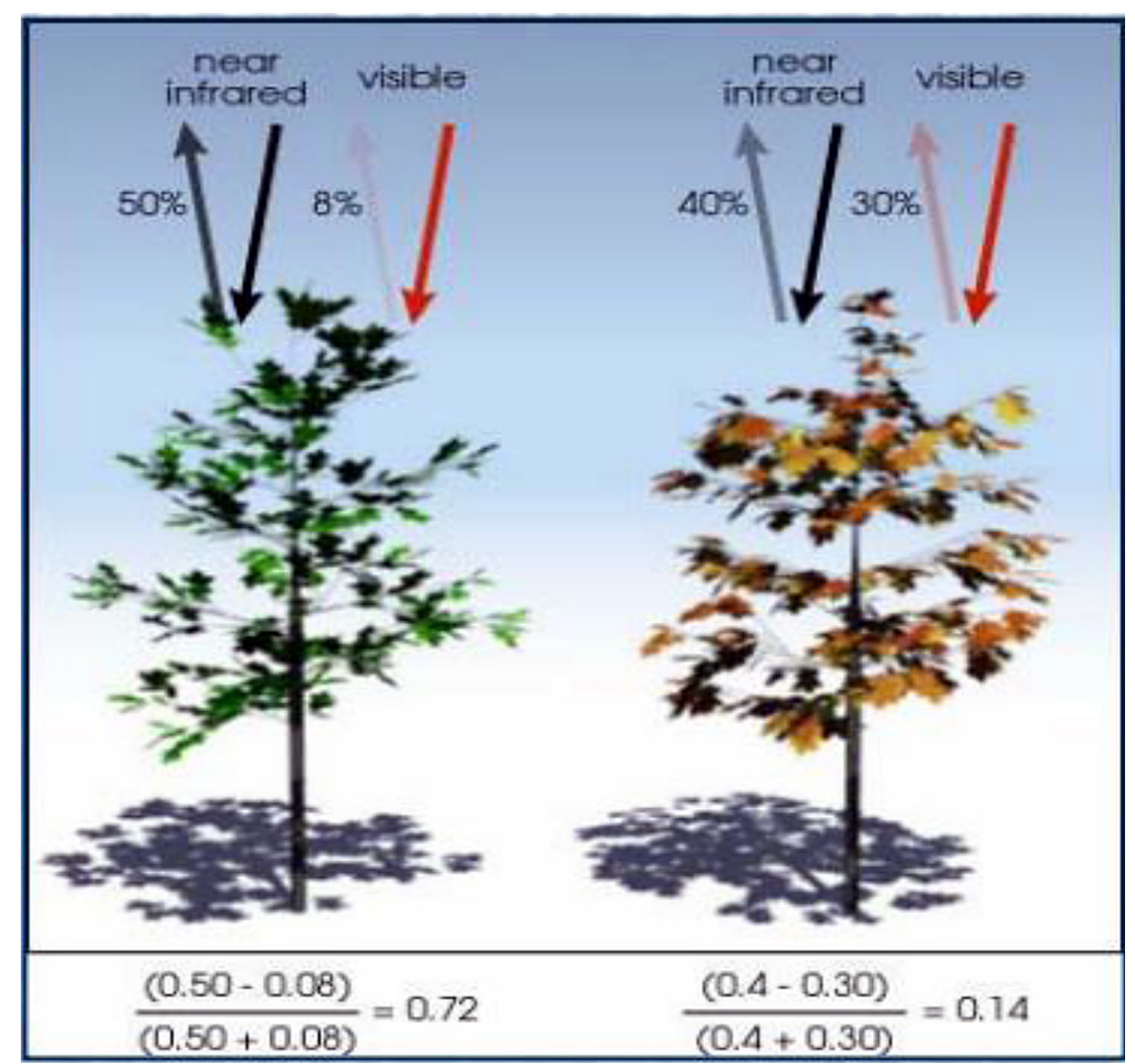

Figure 4. NDVI for healthy and unhealthy vegetation 


$$
\theta^{2}=\frac{S S E}{n-2}
$$

This is called the mean square error MSE of the regression. The standard errors of the parameter estimates are given by:

$$
\begin{gathered}
\theta_{\beta_{0}}=\theta\left(\frac{1}{n}+\frac{\hat{X}^{2}}{\sum\left(X_{i}-\hat{X}\right)^{2}}\right)^{0.5} \\
\theta_{\beta_{1}}=\theta\left(\frac{1}{\sum\left(X_{i}-\hat{X}\right)^{2}}\right)
\end{gathered}
$$

Under the further assumption that the population error term is normally distributed, a researcher can use these estimated standard errors to create confidence intervals and conduct hypothesis tests about the population parameters.

The original Angström regression model is a linear model which connects the ratios of the monthly mean daily solar radiation to clear-day solar radiation on a horizontal surface and the mean fraction of possible sunshine hours (Following the treatment of Duffie and Beckman, 2006):

$$
\frac{H}{H_{c}}=a+b\left(\frac{n}{N_{0}}\right)
$$

where: $H_{c}$ is Mean clear-sky daily solar radiation for the location and month in question.

Page (1964) and others have included $\mathrm{H}_{\mathrm{o}}$ rather than the clear-day solar radiation:

$$
\frac{H}{H_{o}}=a+b\left(\frac{n}{N_{0}}\right)
$$

The values of the extraterrestrial solar radiation can be calculated by:

$$
\begin{aligned}
& H_{o}=\frac{\sin \phi \sin \delta}{\cos \phi \cos \delta}\left(1+0.033 \cos \frac{360 n}{365}\right) * \\
& *\left(\cos \phi \cos \delta \cos w_{s}+\frac{\pi \omega_{s}}{180} \sin \phi \sin \delta\right) \\
& G_{0}=G_{s c}\left(1+0.033 \cos \left(\frac{360 n}{365}\right)\right) \cos \theta_{z}
\end{aligned}
$$

where: $G_{\mathrm{sc}}$ is the solar constant.

$W_{s}$ is the Sunset hour angle, where it is a function of the solar declination and the latitude.

$n$ is the day of the year.

$$
\begin{gathered}
\theta=\cos \phi \cos \delta \cos \omega+\sin \phi \sin \delta \\
\cos \omega_{s}=\frac{\sin \phi \sin \delta}{\cos \phi \cos \delta}=-\tan \phi \tan \delta \\
N_{0}=\frac{2}{15} \cos ^{-1}(-\tan \phi \tan \delta)
\end{gathered}
$$

\section{RESULTS AND DISCUSSION}

This part represents the mathematical model of the empirical coefficients (a) and (b) of Angström linear regression model that can be used to calculate the values of (a) and (b) for six major locations in Jordan from North to South: Irbid, Amman, Azraq, Showbak, Ma'an and Aqaba, (Lati-

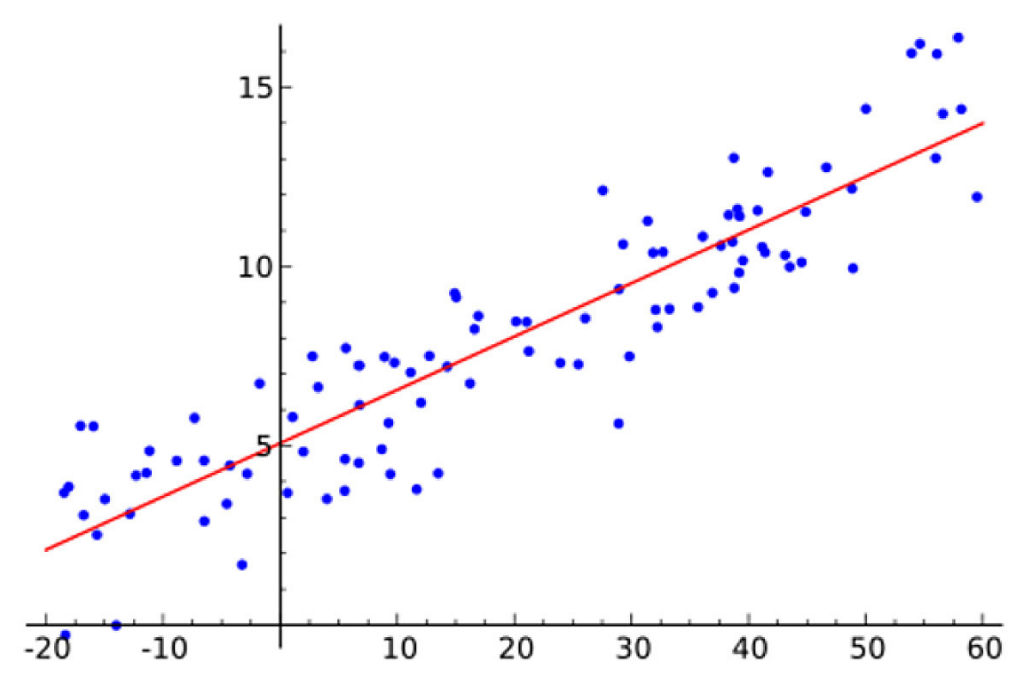

Figure 5. Illustration of linear regression on a data set 
tude 29 degree N) to South (latitude 33.3 Degree N) as shown in Figure 6.

The second part of this section represents the linear Angström regression model for each location. $H$ was calculated for each location by using the values of $a, b, \mathrm{n} / \mathrm{N}_{0}$, and $\mathrm{H}_{0}$ were compared and tested with the measured data.

Several values of $a$ and $b$ were selected for 15 locations which were reported in the literature across Jordan. These values were checked for their applicability. A certain standard for the values was that the regression should have a correlation coefficient higher than 0.9 , The values of albedos were obtained from NEO for each location. The sunshine duration was collected from the literature and was calculated and averaged on yearly bases for each location.

The following equation (32) is the result of the multiple linear regression analysis which represents the dependence of (a) on the sunshine duration and albedo.

$$
a=-0.619+1.19\left(\rho_{g}\right)+0.890\left(\frac{n}{N_{0}}\right)
$$

Multiple regression outputs are studied in order to test the validity. Table 4 shows the regression statistics for the coefficient $a$. The value of the adjusted R-square is 0.91 , which indicates
Table 4. Regression statistics for the coefficient $a$

\begin{tabular}{|l|c|}
\hline \multicolumn{2}{|c|}{ Regression Statistics } \\
\hline Multiple R & 0.960762432 \\
\hline R Square & 0.923064451 \\
\hline Adjusted R Square & 0.91024186 \\
\hline Standard Error & 0.030973589 \\
\hline Observations & 15 \\
\hline
\end{tabular}

that there is a very good relationship between the coefficient (a) and the factors. The error of the studied data is negligible due to the low value of the standard error (0.030973589).

Table 5 shows the analysis of variance (ANOVA). The F-statistic is 71.98 with a probability of $2.07378 \cdot 10^{-7}$ which means that the null hypothesis is rejected and the reasons of the variance of the data is caused by the independent variables, proving the relationship between the dependent and independent variables.

In Table 6 it is clear that the predictor variables of albedo and sunshine duration are significant because both of their p-values are very small, i.e. $1.38 \mathrm{E}-05$ and 0.002722 , respectively.

Table 7 shows the coefficients of the multiple regression equation; the very small values of standard error are an indication of the perfectness of the input data and the other values are within acceptable range.

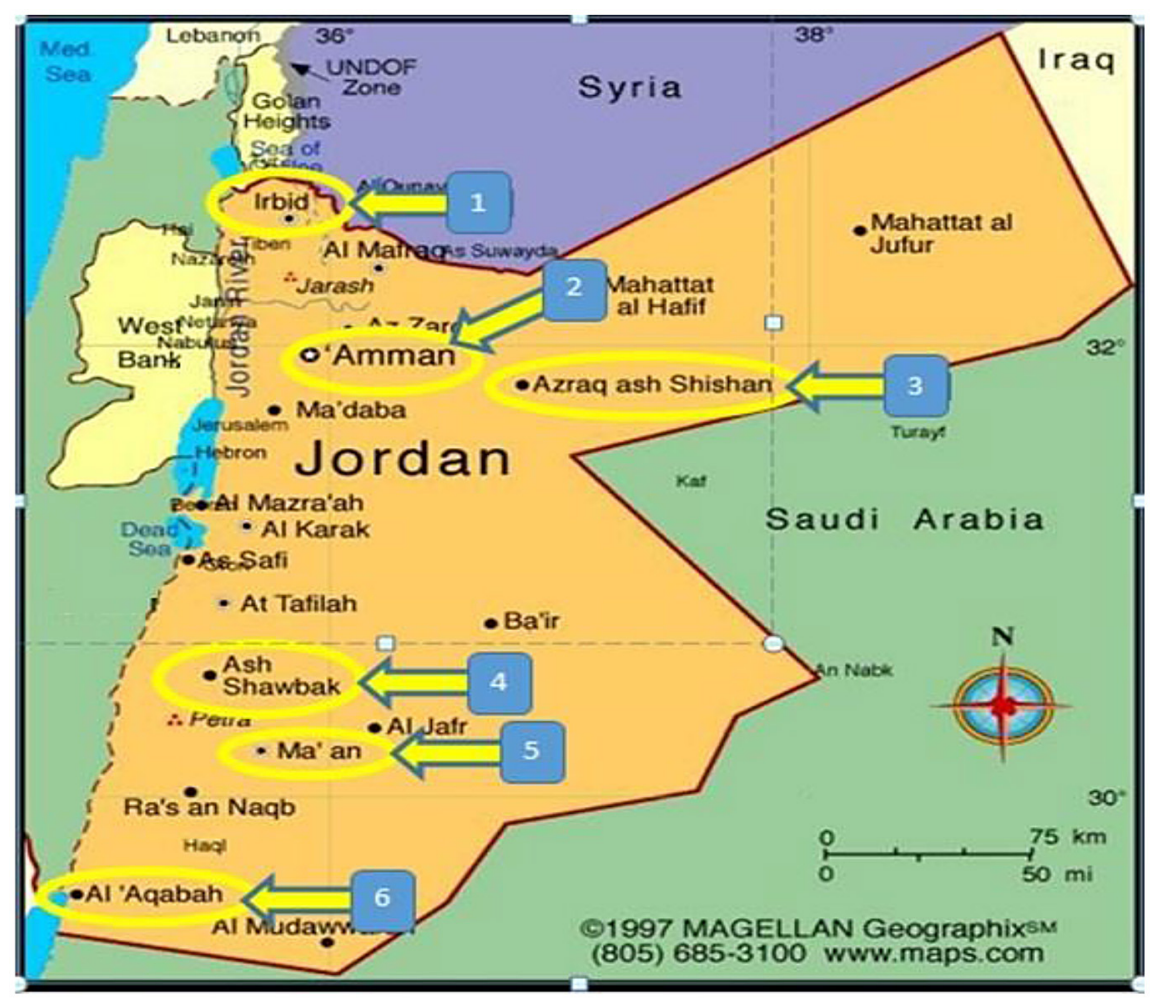

Figure 6. Selected locations in Jordan 
Table 5. Analysis of variance (ANOVA)

Table 6. F-statistics for the coefficient $a$

\begin{tabular}{|c|c|c|c|c|c|}
\hline & df & SS & MS & F & Significance $F$ \\
\hline Regression & 2 & 0.138124041 & 0.06906202 & 71.98735547 & $2.07378 \mathrm{E}-07$ \\
\hline Residual & 12 & 0.011512359 & 0.00095936 & & \\
\hline Total & 14 & 0.1496364 & & & \\
\hline
\end{tabular}

Table 7. T-test and regression equation for the coefficient $a$

\begin{tabular}{|c|c|c|c|c|c|c|c|c|}
\hline & Coefficients & $\begin{array}{c}\text { Standard } \\
\text { Error }\end{array}$ & t Stat & P-value & Lower 95\% & Upper 95\% & $\begin{array}{c}\text { Lower } \\
95.0 \%\end{array}$ & $\begin{array}{c}\text { Upper } \\
95.0 \%\end{array}$ \\
\hline Intercept & -0.711082 & 0.188939 & -3.7635 & 0.002703 & -1.122746 & -.299418 & -.12274577 & -0.2994187 \\
\hline$\rho_{g}$ & 1.059927549 & 0.150821711 & 7.02768551 & $1.38 \mathrm{E}-05$ & 0.7313153 & 1.3885398 & 0.73131527 & 1.38853983 \\
\hline$\left(n \cdot N_{0}^{-1}\right)$ & 1.052226799 & 0.279861878 & 3.75980754 & 0.002722 & 0.4424601 & 1.6619934 & 0.44246015 & 1.66199345 \\
\hline
\end{tabular}

The following equation (33) is the result of the multiple linear regression analysis which represents the dependence of $a$ on the sunshine duration and albedo.

$$
b=1.52-1.23 \rho_{g}-1.00\left(\frac{n}{N_{0}}\right)
$$

Multiple regression outputs are studied in order to test the goodness. Table 8 shows the regression statistics for the coefficient $b$. The value of the adjusted R-square is 0.80 . It can be concluded that there is a very good relationship between the coefficient $b$ and the factors. The error of the studied data is negligible due to the small value of the standard error (0.05101747).

Table 9 shows the F-statistics is 29.8848 with a probability of $2.18498 \mathrm{E}-05$, which means that the null hypothesis is rejected and the reasons of the variance of the data is caused by the independent variables which prove the relationship between the dependent and independent variables.

Table 8. Regression statistics for the coefficient $b$

\begin{tabular}{|l|c|}
\hline \multicolumn{2}{|c|}{ Regression Statistics } \\
\hline Multiple R & 0.91257771 \\
\hline R Square & 0.83279807 \\
\hline Adjusted R Square & 0.80493109 \\
\hline Standard Error & 0.05101747 \\
\hline Observations & 15 \\
\hline
\end{tabular}

Table 11 summarizes the previous analysis of the coefficients $a$ and $b$ with the correlation coefficient and the standard error estimation for each equation.

Table 12 provides the calculated values of Angström coefficients $a$ and $b$ using the developed equations 5 and 6 for each location. The values of albedo were obtained from NEO and albedo Tables. The following Figures 13 through 18 show a comparison between measured and theoretically estimated (predicted) solar radiation for the six Jordanian locations. The equation estimates are statistically significant as the critical value of $\mathrm{t}$-stat is 0.338 , which is between 1.96 and -1.96 . The values of RMSE and MBE are in a very acceptable range, as shown in Table 13.

The equation estimates are statistically significant as the critical value of t-stat is 0.791 , which ranges between 1.96 and -1.96 . The values of RMSE and MBE are within a very acceptable range as shown in Table 13. The equation estimates are statistically significant, as the critical value of t-stat is 1.44 which ranges between 1.96 and -1.96 . The values of RMSE and MBE are within a very acceptable range as shown in Table 13. The equation estimates are statistically significant, as the critical value of t-stat is 1.374 , which ranfes between 1.96 and -1.96 . The values of RMSE and MBE are within a very acceptable range, as shown in Table 13. 
Table 9. F-statistics for the coefficient $b$

\begin{tabular}{|c|c|c|c|c|c|}
\hline & df & SS & MS & F & Significance F \\
\hline Regression & 2 & 0.155567 & 0.077784 & 29.8848 & $2.18498 \mathrm{E}-05$ \\
\hline Residual & 12 & 0.0312334 & 0.002603 & & \\
\hline Total & 14 & 0.1868004 & & & \\
\hline
\end{tabular}

Table 10. T-test and regression equation for the coefficient $b$

\begin{tabular}{|c|c|c|c|c|c|c|c|c|}
\hline & Coefficients & Standard Error & t Stat & P-value & Lower 95\% & Upper 95\% & Lower 95.0\% & Upper 95.0\% \\
\hline Intercept & 1.62820698 & 0.311207379 & 5.2319 & 0.00021 & 0.9501443 & 2.3062696 & 0.95014435 & 2.30626961 \\
\hline$\rho_{g}$ & -1.0933889 & 0.248422683 & -4.4013 & 0.00086 & -1.634655 & -0.552122 & -1.6346554 & -.55212238 \\
\hline$\left(n \cdot N_{0}^{-1}\right)$ & -1.1844041 & 0.460968373 & -2.5694 & 0.02457 & -2.188768 & -0.18004 & -2.1887679 & -.18004027 \\
\hline
\end{tabular}

Table 11. Summary of Angström coefficients $a$ and $b$ equations

\begin{tabular}{|c|c|c|c|}
\hline Relation & R-quare & Adjusted R-square & Standard error of estimation (S) \\
\hline$a=-0.619+1.19 \rho_{g}+0.890\left(n \cdot N_{0}^{-1}\right)$ & 0.93 & 0.86 & 0.03 \\
\hline$b=1.52-1.23 \rho_{g}-1.00\left(n \cdot N_{0}^{-1}\right)$ & 0.89 & 0.82 & 0.05 \\
\hline
\end{tabular}

Table 12. Regression coefficients and albedo for 6 Jordanian locations.

\begin{tabular}{|c|c|c|c|}
\hline Location & $(\mathrm{a})$ & $(\mathrm{b})$ & Albedo \\
\hline Irbid & 0.2 & 0.61 & 0.167 \\
\hline Amman & 0.29 & 0.51 & 0.2 \\
\hline Azraq & 0.29 & 0.53 & 0.25 \\
\hline Showbak & 0.35 & 0.47 & 0.26 \\
\hline Ma'an & 0.52 & 0.27 & 0.38 \\
\hline Aqaba & 0.35 & 0.45 & 0.23 \\
\hline
\end{tabular}

Table 13. Values of the statistical error tests

\begin{tabular}{|c|c|c|c|}
\hline Location & RMSE & MBE & t-stat \\
\hline Irbid & 0.7 & 0.071 & 0.338 \\
\hline Amman & 0.6 & 0.011 & 0.064 \\
\hline Azraq & 0.925 & -0.368 & 1.44 \\
\hline Showbak & 0.69 & -0.264 & 1.374 \\
\hline Ma'an & 0.42 & -0.062 & 0.497 \\
\hline Aqaba & 0.53 & 0.253 & 1.796 \\
\hline
\end{tabular}

The equation estimates are statistically significant, as the critical value of t-stat is 0.497 , which ranges between 1.96 and -1.96 . The values of RMSE and MBE are within a very acceptable range as shown in Table 13. The equation estimates are statistically significant, as the critical value of t-stat is 1.796 , which ranges between 1.96 and -1.96. The values of RMSE and MBE are within a very acceptable range, as shown in Table 13.

From equations $(32,33)$, one can see that a correlation exists between the constant $a$ and $b$, the average related sunshine duration and the ground albedo. The current method is established on this relationship and is therefore superior to the methods that use coefficients of presumed worldwide validity. This new method provides an estimation with the error between the estimation and the measured values in case of outliers isolation lesser than $6.3 \%$ and overwhelmingly lesser than that for values of $\left(\mathrm{n} / \mathrm{N}_{0}\right)$ ranging between $0.53-0.92$, (5.17), which are summed up in Table 14.

For the third location (Azraq), March and April are characterized by the highest abs. error $\%$ 
Table 14. Max. and min. mean percentage error for the selected locations

\begin{tabular}{|c|c|c|}
\hline Location & Min. error \% & Max. error \% \\
\hline Ibrid & 0.63 & 6.3 \\
\hline Amman & 0.05 & 5.72 \\
\hline Azraq & 0.03 & 9.3 \\
\hline Showbak & 0.54 & 5.38 \\
\hline Ma'an & 0.12 & 3.23 \\
\hline Aqaba & 0.28 & 5.00 \\
\hline
\end{tabular}

$9.3,8.01$, respectively, because the recorded data for these months are relatively high and are believed to be outliers.

Reliance of the coefficients on the related $\left(\mathrm{n} / \mathrm{N}_{0}\right)$ was to be anticipated considering the nature of the constants, which depend on the climatological and vegetation classifications. Angestrom (1956) has mentioned that the average related sunshine duration in a specific location is a sign indicating the appearance of elevated clouds:

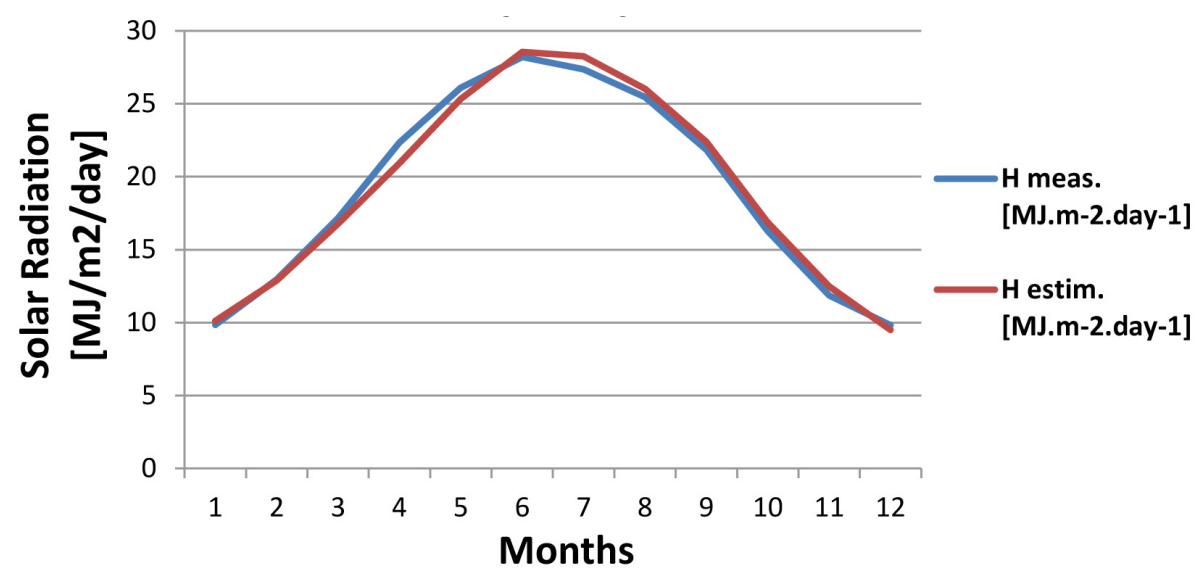

Figure 7. Variation of measured vs. estimated solar radiation with time of the year for Irbid

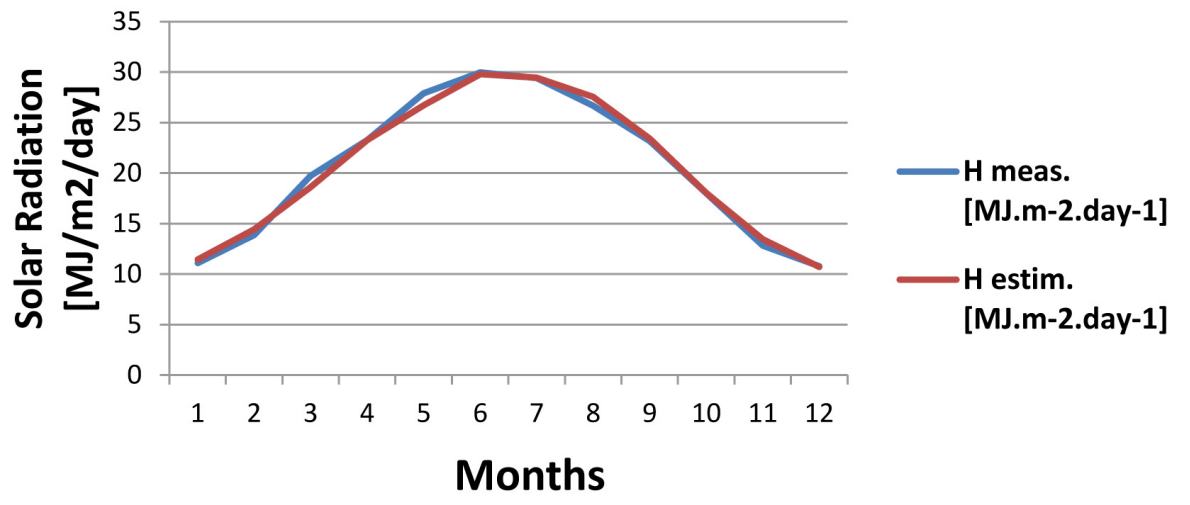

Figure 8. Variation of measured vs. estimated solar radiation with time of the year for Amman

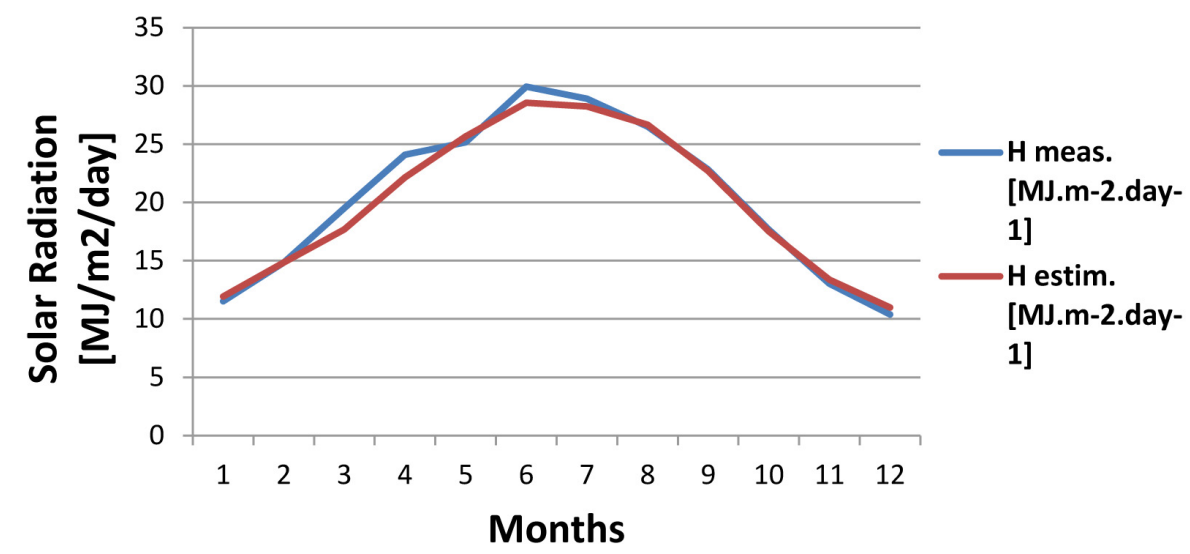

Figure 9. Variation of measured vs. estimated solar radiation with time of the year for Azraq 


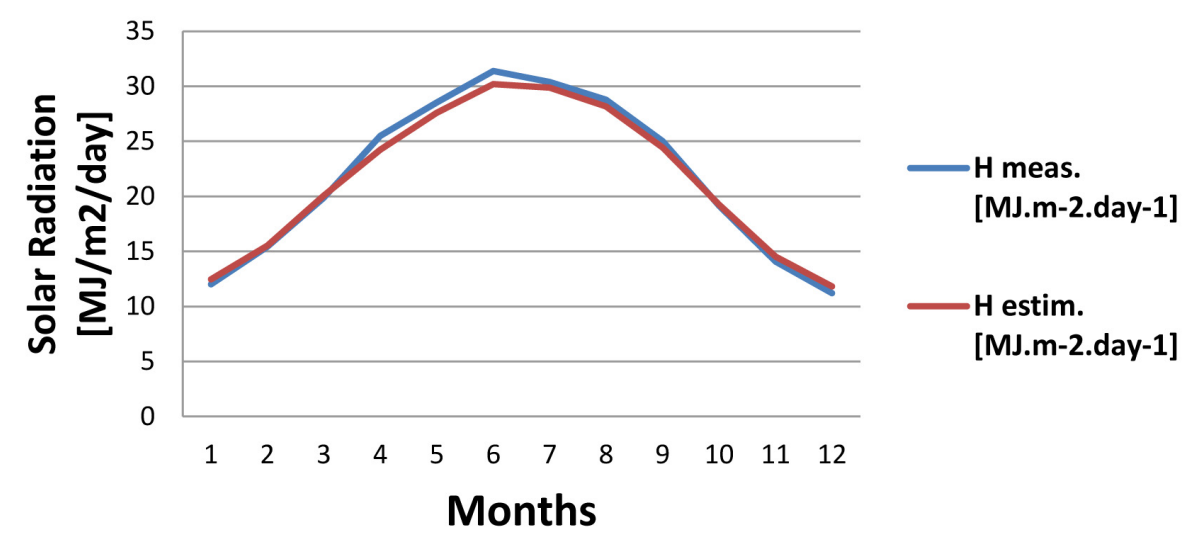

Figure 10. Variation of measured vs. estimated solar radiation with time of the year for Showbak

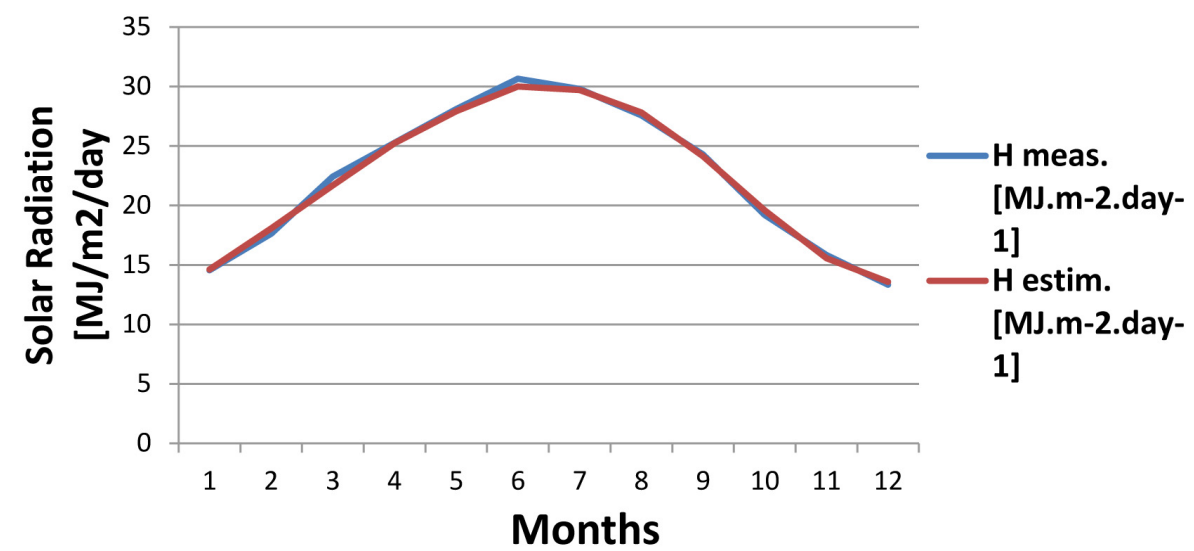

Figure 11. Variation of measured vs. estimated solar radiation with time of the year for Ma'an

the higher $\left(\mathrm{n} / \mathrm{N}_{0}\right)$, the higher the clouds. The elevated clouds are drier than the lower clouds so they absorb less shortwave radiation resulting in more sunlight that breaks through the clouds.

The vegetation classification (i.e vegetation type, greenness level and intensity) for a specific location is inversely proportional to albedo, the higher the vegetation level, the lower the amount of reflected shortwave radiation (Albedo), as shown in Figure 4 through NDVI. On the other hand, a reliance of the coefficients on the relative ground albedo is also expected for the same reason that is mentioned above, which results from the nature of the coefficients, Increasing the ground albedo will lead to an increase of the reflected shortwave solar radiation. Ground albedo is proportional to $a$ coefficient and has an inverse relationship with $b$ coefficient, as shown in Table 11, and the equations in Table 12.

As a result, Ma'an location has the highest albedo 0.38 due to the very poor vegetation level in that location and the sandy ground cover among the selected location. On the other hand, Irbid has the lowest albedo 0.167 due to the high- er vegetation level (trees and crops) as shown in Table 3 and Figure 5.

The equation estimates are statistically significant for the selected locations due to the values of t-test which are in the range of $1.96-$ -1.96. The values of RMSE are within a very acceptable range which is close to zero; however, the higher RMSE is for Azraq location (0.925) due to a large deviation for March and April which produce a significant increase in RMSE. The values of MBE are very small and close to zero; however, for Azraq location it is relatively high $(-0.368)$ due to the same reason which was mentioned earlier.

It can be clearly seen the curves of the measured and estimated $\mathrm{H}$ from the Figures 13-18 for the selected locations are characterized by a very good match.

\section{CONCLUSIONS}

From the analysis conducted in this work, the following conclusions can be formualted: 
1) Angström coefficients $a$ and $b$ depend on the climate and vegetation classifications; the climate classification is expressed through sunshine duration and the vegetation classification is expressed through the ground albedo for a specific location.

2) Dependence of Angström coefficients $a$ and $b$ on the sunshine duration and the ground albedo has been verified.

3) The developed multiple linear regressions which correlate Angström coefficients $a$ and $b$ with sunshine duration and ground albedo are in the following form:

$$
\begin{aligned}
& a=-0.619+1.19 \rho_{g}+0.890\left(\frac{\mathbf{n}}{\mathbf{N}_{0}}\right) \\
& b=1.52-1.23 \rho_{g}-1.00\left(\frac{\mathbf{n}}{\mathbf{N}_{0}}\right)
\end{aligned}
$$

and are recommended for calculating Angström linear regression coefficients $a$ and $b$ for the locations in Jordan where solar radiation data are not available, as well as in the locations where sunshine duration is in the range of $0.5-0.92$.

4) The coefficients of Angström linear regression model were calculated for six main locations in Jordan across the country from the North to the South. These coefficients are:

- Irbid: $\quad a=0.2, \quad b=0.61$

- Amman: $a=0.29, b=0.51$

- Azraq: $\quad a=0.29, b=0.53$

- Showbak: $a=0.35, b=0.47$

- Ma'an: $\quad a=0.52, b=0.27$

- Aqaba: $\quad a=0.35, b=0.45$

The percentage error of using the calculated constants to estimate $H$ by Angström linear regression model will lie within the range of $0.05-6.3 \%$.

\section{REFERENCES}

1. Ababsa, 2013. Atlas of Jordan, http://books. openedition.org/ifpo/4560.

2. Alan K. Betts and John H. Ball 1997. Albedo over the boreal forest. Journal of Geophysical Society.

3. Al-Bakri J.T., Salahat M., Suleiman A., Suifan M., Hamdan M.R., Khresat S., Kandakji T., 2013. Impact of Climate and Land Use Changes on Water and Food Security in Jordan: Implications for Transcending "The Tragedy of the Commons". Sustainability, 5(2), 724-748.

4. AL-Eisawi, D.M. 1996. Vegetation of Jordan. Book published By UNESCO (ROSTAS), Cairo Office. Cairo.
5. Al-Muhtaseb, 2012. Development of a regression model for solar radiation in Jordanian site and assessment of related solar energy.

6. Alsaad M.A., 1990. Characteristic distribution of global solar radiation for Amman, Jordan, Solar and Wind Technology, 7(2/3), 261-266.

7. Alsaad M.A., 1990. Improved correlation for predicting global radiation for deferent location in Jordan, Int, J. Solar Energy, Vol. 8, 97-107.

8. Alsaad M.A., 1990. Solar radiation map for Jordan Solar, Solar and Wind Technology, 7(2/3), 267-275.

9. Alsaad M.A., 1990. The applicability of hourly solar radiation models to Amman, Jordan, Solar and wind technology, 7(4), 473-480.

10. Alsaad M.A., 1991. Correlations for predicting average Global solar radiation incident on a horizontal surface in Amman, Jordan, J. King Saud Univ., Eng. Sci., 3(1), 121-134.

11. Andrews, Rob W.; Pearce, Joshua M. 2013. The effect of spectral Albedo on amorphous silicon and crystalline silicon solar photovoltaic device performance, Solar Energy, 91, 233-241.

12. Angström, 1924. Solar and Terrestrial Radiation, Quarterly Journal of the Royal Meteorological Society, Vol. 50, No. 210.

13. Assi A. and Jama M., 2009. Estimating Global Solar Radiation on Horizontal from Sunshine Hours in Abu Dhabi - UAE.

14. Duffie, J. and Beckman, W. 2013. Solar Engineering of Thermal Processes. John Wiley and sons INC., New York.

15. El-Sebaii and Trabea A.A. 2005. Estimation of Global Solar Radiation on Horizontal Surfaces Over Egypt. Egypt. J. Solids, 28(1), 163-175.

16. Gariepy J., 1980. Estimation of global solar radiation. International Report, Service of Meteorology, Government of Quebec, Canada.

17. Gopinathan K.K., 1988. A general formula for computing the coefficients of the correlations connecting global solar radiation to sunshine duration. Solar Energy, 41, 499-502.

18. Hamdan M.A. and N. Gazzawi, 1993. The effect of clouds on solar radiation, Energy Convers. Manage., 34(1), 29-32.

19. Hamdan M.A., 1994. Solar Radiation Data for Amman, Applied Energy, pp. 87-96.

20. Hammad M.A. and Al-Sayeh A.I., 1991. Diffuse and Global solar radiation correlations for Jordan, Int. J. Solar Energy, Vol. 10, 145-154.

21. Hay J.E., 1979. Calculation of monthly mean solar radiation for horizontal and inclined surfaces, Solar Energy, 23, 4, 301-307.

22. Iqbal, M., 1983. Introduction to solar radiation. 
New York: Academic

23. Jain P.C., 1988. Estimation of monthly average hourly global and diffuse irradiation. Solar Wind Technol. 5, 7 .

24. Jain S., Jain P.C., 1988. A comparison of the Angström-type correlations and the estimation of monthly average daily global irradiation. Solar Energy.

25. Jamil Ahmad M., Tiwari G.N., 2010. Solar radiation models - review. International journal of energy and environment, 1(3), 513-532.

26. Liu B.Y. and Jordan R.C., 1960. The Interrelationship and Characteristic Distribution of Direct, Diffuse, and Total Radiation, Solar Energy, 4(3), 1-19.

27. Liu B.Y. and Jordan R.C. 1940. The interrelationship and characteristic distribution of direct, defuse, and total solar radiation. Solar Energy, 4(1).

28. Long, G., 1957. The bioclimatology and vegetation of East Jordan. Rome, UNESCO/ FAO.

29. Markvart T. and Castazer L., 2003. Practical Handbook of Photovoltaics: Fundamentals and Applications.

30. Page J.K., 1961. The estimation of monthly mean values of daily total short wave radiation on vertical and inclined surface from sunshine records for latitudes 40N-40S. Proceedings of UN Conference on New Sources of Energy, 4(598), 378-390.
31. Rietveld M. 1978. A new method for estimating the regression coefficients in the formula relating solar radiation to sunshine. Agricultural Meteorology 19, 243-252.

32. Starr M.R., Palz W., 1983. Photovoltaic power for Europe: an assessment study, Commission of the European Communities. (http://www.ftexploring. com/solar-energy/direct-and-diffuse-radiation. htm\#fn2)

33. Stone, R.J., 1993. Improved statistical procedure for the evaluation of solar radiation estimation models. Solar Energy Vol. 51, 289.

34. Tetzlaff, G., 1983. Albedo of the Sahara. Cologne University Satellite Measurement of Radiation Budget Parameters. pp. 60-63.

35. Tiwari, R.F and Sangeeta, T.H. 1997. Solar Energy, 24(6) 89-95.

36. Togrul, I.T., 1998. Comparison of statistical performance of seven sunshine-based models for Elazig, Turkey, Chemica Acta Turuca, 26, 37.

37. Zabara K., 1986. Estimation of the global solar radiation in Greece. Solar and Wind Technology, 3(4), 267-272.

38. Zaid Jibril, 1991. Estimation of solar radiation over Jordan-Predicted tables, Renewable Energy, Vol. 2, 277-291. 